\title{
Comparing Four Softwares Based on ISO 9241 Part 10
}

\author{
Reza Safdari • Hussein Dargahi • Leila Shahmoradi • \\ Ahmadreza Farzaneh Nejad
}

Received: 18 April 2011 / Accepted: 28 June 2011 / Published online: 14 July 2011

(C) The Author(s) 2011. This article is published with open access at Springerlink.com

\begin{abstract}
Evaluation of Iran's HIS (hospital Information System) ergonomic quality using IsoMetric 9241 part 10 and compared results of that evaluation with results of ergonomic quality evaluation other softwares which evaluated by IsoMetric 9241 part 10. This research study was conducted in two stages. In the first stage, the researchers evaluated the HIS of 13 hospitals in Iran using ISO 9241 part 10, and in the second stage, they compared the evaluation results with the following softwares: a) IS$\mathrm{H}^{*}$ med (evaluated by Hamborg et al. 2004) b) SAP-HR (evaluated by Gruber 2000) c) Microsoft Word for Windows, Version 2 (evaluated by Gediga et al. 1999). For first stage used usability questionnaire called IsoMetrics which is based on the international standard ISO 9241 Part 10. This questionnaire is including 75 items based on the seven principles. Data analyzed using SPSS and Excel. The comparison between HIS and IS-H*med reveal that the former is significantly more usable than the latter in terms of all IsoMetrics sales. The HIS also proved to be significantly more applicable than SAP-HR in terms of such IsoMetrics scales as "suitability for task," "suitability for learning", "Error tolerance" and
\end{abstract}

\footnotetext{
R. Safdari $\cdot$ H. Dargahi $\cdot$ L. Shahmoradi $(\bowtie) \cdot$ A. Farzaneh Nejad School of Allied Medical Sciences,

Tehran University of Medical Sciences,

Tehran, Iran

e-mail: Leilashahmoradi1@gmail.com

L. Shahmoradi

e-mail: Lshahmoradi@tums.ac.ir

R. Safdari

e-mail: rsafdari@tums.ac.ir

H. Dargahi

e-mail: hdargahi@sina.tums.ac.ir

A. Farzaneh Nejad

e-mail: farzana@sina.tums.ac.ir
}

"learning ability". However, HIS was found to be significantly less usable than Microsoft Word. The results of the study show that compared with the mentioned three softwares, Iran's hospital information system enjoys an average ergonomic quality. Therefore, it is recommended that the users' comments and expectations be considered more when information systems are designed and developed.

Keywords Healthcare - Information systems · Evaluation · Hospital information system (HIS) - Ergonomic quality . Software quality

\section{Introduction}

Information Systems are increasingly employed in healthcare industry. Therefore, it is necessary for the designers of information technology and communication systems to assess them continuously [1]. However, it is impossible to evaluate such systems without first analyzing their users' understanding of them. Moreover, users' satisfaction guarantees the successful implementation of information systems [2].

An information system is a combination of technology, individuals and processes used to transport, store, manipulate and present data [3]. Health information refers to the organized data related to a patient or a group of patients [4].

Health information systems were presented in early 1970's [5]. Healthcare information systems include data and concepts in health services given to patients to improve the management of such services [6]. Hospital information systems have many functions such as patients' admission, transfer and discharge as well as financial and clinical affairs [6-8]. There are many advantages to health information services: the enhancement of medical care quality and 
Table 1 Software's evaluated by IsoMetrics

\begin{tabular}{|c|c|c|c|c|}
\hline Authors & Year of evaluation & Software name & Number of users & Software's application \\
\hline Hamborg et al. & 2004 & IS-H*med & 182 & $\begin{array}{l}\text { - Creation of release plan, review of diagnostic } \\
\text { and laboratory findings, documentation of } \\
\text { diagnostic findings, diagnostic related group } \\
\text { (DRG), medical examination order, } \\
\text { documentation of medical examinations, nursing } \\
\text { category, and ordering meals. } \\
\text { - Evaluation done at the University Hospital of } \\
\text { Heidelberg, Department of Internal Medicine. }\end{array}$ \\
\hline Gruber & 2000 & SAP-HR & 28 & $\begin{array}{l}\text { - Support of many tasks in the field of human } \\
\text { resource management such as personnel time } \\
\text { management, training and event management, } \\
\text { and payroll accounting }\end{array}$ \\
\hline Gediga et al. & 1999 & $\begin{array}{l}\text { Microsoft Word } \\
\text { for Windows } \\
\text { (Version 2) }\end{array}$ & 55 & $\begin{array}{l}\text { —WinWord is a word processing software by } \\
\text { Microsoft } \subseteq\end{array}$ \\
\hline
\end{tabular}

reduction of costs and errors. Most evaluations performed in this field have focused on the reduction of costs and the improvement of quality [9]. Certain studies, however, have emphasized the technical and social aspects [10].

Hospital information systems (HIS) have many advantages: they increase the quality of medical care and reduce costs and clinical errors [11]. However, despite all these benefits, information systems have also some problems [12]. To recognize and remove such problems, it is necessary to evaluate HIS permanently. In fact, evaluation in an endless process [13] and its results can be used to make decisions regarding the required investments for designing hospital information systems [14].

It is necessary to consider the evaluation of hospital information systems before, during and after developing them [15]. Financial aspects and patient satisfaction are also important factors in the evaluation of HIS [16].
There are many articles focusing on the evaluation of health information systems, as well as their indicators and outcomes [17]. Littlejohns et al. (2003) evaluated the integrated computer system in South Africa [18]. In their evaluation, they focused on optimal education, change management and support, project management, improvement of the link systems, maintenance of information confidentiality, standardization of processes to manage patients, increase of revenue and cost of each service package.

UK Health Informatics Institute presents a framework for evaluating health information systems. In this framework, questions, tools, techniques and manner of evaluation are provided [19]. A system is considered weak if it does not provide its users with proper information. For the information system to be successful, not only the users' information needs should be met, but the manner of interaction between the system and its users should also be considered.

Table 2 The seven principles of ISO 9241 part 10

Suitability for the task

Self-descriptiveness

Controllability

Conformity with user expectations

Error tolerance

Suitability for individualization

Suitability for learning
Software is suitable, if it supports the user to realize his tasks effectively and efficiently.

Software is self-descriptive, if every step is understandable in an intuitive way, or, in case of mistakes supported by immediate feedback.

Software is controllable, if the user is able to start the sequence and influence its direction as well as speed till he reaches his aim.

Software conforms with the user's expectations, if it is consistent, complying with the characteristics of the user, e.g. taking into account the knowledge of the user in that special working area, accounting education and experience as well as general acknowledged conventions.

Software is error tolerant, if it requires no or just minimal additional effort despite obvious faulty steering or wrong input.

Software is suitable for individualization, if the system allows customizing according to the task as well as regarding the individual capabilities and preferences of a user.

Software supports the suitability of learning, if the user is accompanied through different states of his learning process and the effort for learning is as little as possible. 
A technology is accepted by users if it is usable and helpful [11]. In other words, the quality of a system depends on its usability, availability, reliability, adaptability and response time [20]. The purpose of usability evaluation is to determine the strong and weak points of information systems and to provide guidelines for the improvement of their application [21]. Ergonomic quality of software systems should be evaluated with reference to their application context (including user, task, equipment and environment), user type and users' computer experience.

ISO 9241 presents the ergonomic requirements for designing software. ISO 9241 has 17 parts and seven principles. The 17 parts consist of general introduction, general guidance on task requirements, visual display requirements, keyboard requirements, workstation layout and postural requirements, environmental requirements, display requirements with reflection, requirements for displayed colors, requirements for non-keyboard input devices, dialog principals, usability statements, presentation of information, user guidance, menu dialogs, command dialogs, direct manipulation dialogs, and form filing dialogs. And the seven principles are suitability for the task, self-descriptiveness, controllability, conformity with user expectations, error tolerance, suitability for individualizations, and suitability for learning. These seven principles are considered for usability evaluation.

IsoMetrics is a reliable and suitable technique for HIS evaluation $[15,21]$. It is a technique to evaluate the usability of software applications with respect to the international standard ISO 9241 part 10. IsoMetrics is user-oriented. Due to the two versions of IsoMetrics evaluation-formative and summative-, two kinds of IsoMetrics - short and long-are presented, [21] Which apply to summative and formative evaluations, respectively. Summative assessment is conducted some years after the implementation of information system [14]. Formative or constructive assessment is more qualitative. It is conducted during the engineering life cycle of the information system or before its further development [21].

In recent years, many researchers have evaluated usability of clinical information systems [22-26]. The results of the studies conducted on the usability evaluation

Table 3 Frequency and percentage of the user types

\begin{tabular}{llc}
\hline User type & Frequency & Percentage \\
\hline Nurses & 98 & 37.3 \\
Department secretaries & 88 & 33.4 \\
Users of paraclinic units & 77 & 29.3 \\
Total & $285^{\mathrm{a}}$ & 100 \\
\hline
\end{tabular}

${ }^{\mathrm{a}}$ There were 22 unidentified user types

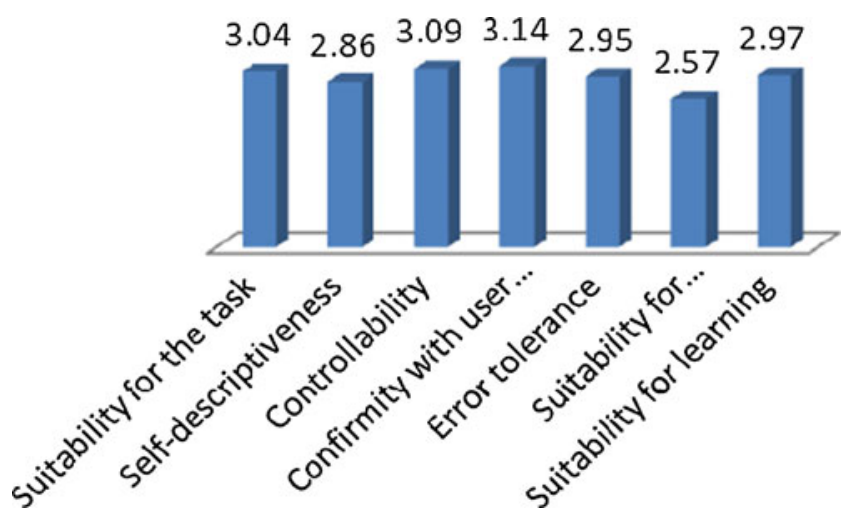

Fig. 1 HIS IsoMetrics scale means

of health information systems show that little attention has been paid to usability [27-30].

IS-H*med, SAP-HR and Microsoft Word for Windows (Version 2.0) are the three softwares which were evaluated using IsoMetrics in 1999, 2000, and 2004, respectively [15, 21]. The year of evaluation, name, number of users, and application of each software are presented in Table 1 .

In this article, the evaluation results of the three softwares-IS-H*med, SAP-HR and Microsoft Word (Version 2.0) - are compared with that of Iran's HIS.

\section{Materials and methods}

In this research used a usability questionnaire based on ISO 9241 part 10 so that the usability of hospital information systems could be investigated. The questionnaire consisted of 75 items based on the seven principles of suitability for the task, self-descriptiveness, controllability, conformity with user expectations, error tolerance, suitability for individualization, and suitability for learning. These principles are defined briefly in Table 2 [21].

It is to be mentioned that the 75-item questionnaire included 15 questions for suitability for the task, 12 questions for self-descriptiveness, 11 questions for controllability, 8 questions for conformity with user expectations, 15 questions for error tolerance, 6 questions for suitability for individualization, and 8 questions for suitability for learning.

Each question of the IsoMetrics Questionnaire is assessed on a five-point rating scale starting from 1 ("predominantly disagree") to 5 ("predominantly agree"). The data were analyzed using SPSS and Excel softwares. Questionnaires with more than $20 \%$ of missing data (more than 15 unanswered items) were not analyzed [15]. In case of less than or equal to 15 omissions, the missing values were replaced by the mean scale value (3) of the items. Some items of the questionnaire (A1, A8, T12, E8, F1, F7, F14, L1, and L7) were negative in nature. The values of 
Table 4 Comparison between HIS and IS-H*med

\begin{tabular}{|c|c|c|c|c|c|c|}
\hline \multirow[t]{2}{*}{ IsoMetrics scale } & \multicolumn{2}{|l|}{ Mean } & \multirow[t]{2}{*}{$T$} & \multirow[t]{2}{*}{$\mathrm{df}$} & \multirow[t]{2}{*}{$p$} & \multirow[t]{2}{*}{$d$} \\
\hline & IS-H*med & HIS & & & & \\
\hline Suitability for the task & 2.77 & 3.04 & 2.55 & 284 & $<0.000$ & 0.27 \\
\hline Self-descriptiveness & 2.68 & 2.86 & 4.38 & 284 & $<0.001$ & 0.18 \\
\hline Controllability & 2.97 & 3.09 & 3.00 & 284 & 0.003 & 0.12 \\
\hline Conformity with user expectations & 3.06 & 3.14 & 1.84 & 284 & 0.065 & 0.08 \\
\hline Error tolerance & 2.85 & 2.95 & 2.80 & 284 & 0.005 & 0.109 \\
\hline Suitability for individualization & 2.12 & 2.57 & 7.78 & 284 & $<0.001$ & 0.45 \\
\hline Suitability for learning & 2.84 & 2.97 & 3.17 & 284 & .0002 & 0.13 \\
\hline
\end{tabular}

these items were inverted by the transformation ri' $=6-$ ri for further analysis [21]. For statistical analyses, one-sample $t$-test and $p$-values were used.

This research was conducted in two stages. First, the hospital information system (HIS) of Iran was evaluated. Then, the results of the first stage were compared with those of the three softwares which were evaluated by the same IsoMetrics. A multi-step sampling was conducted for the first stage of the study; that is, first the capital's hospitals having computerized hospital information systems were determined. Then a list of companies providing such systems was prepared. And finally, for each company, one hospital was selected.

These companies included Rayavaran, Tarrahane Boo Ali, Rahavard Rayane, Data Link Informatics, Teb-o Rayane, Tirajhe Rayane, Pouya Padideh, Kian Tak, Smart Chip. And the hospitals consisted of Firoozgar, Toos, Shariati, Rasoul, Hashemi Nejad, Children Medical Center, Kasra, Vali-e Asr, Kashani, Day, Hazrat-e Fatima, Atieh, and Imam Reza.

To conduct the second stage of the study, the HIS IsoMetrics mean value were compared with those of the three other applications, i.e., IS-H*med, SAP-HR, and Microsoft word. IS-H*med, SAP-HR, and Microsoft word were the softwares evaluated using ISO 9241 part 10 by Hamborg et al. in 2004, Gruber in 2000, and Gediga et al. in 1999, respectively.
The viewpoints of three types of users (nurses, users of paraclinic units, and department secretaries) were studied using a standardized IsoMetrics questionnaire. For that purpose, one nurse was selected for every ten beds and one user from every paraclinic unit. However, the viewpoints of all department secretaries were studied. In total, 285 individuals including 98 nurses, 88 department secretaries and 77 users of paraclinic units filled out the standardized IsoMetrics questionnaire. There were 22 unidentified user types. In Table 3, the frequency and percentage of the three user types are presented. It is to be mentioned that 22 of the questionnaires were filled out by unidentified user types.

More than half of the users $(56.8 \%)$ were nurses. Also, most users $(62.5 \%)$ had worked for $1-9$ years and 57 users (31\%) for $10-19$ years in their current positions. In addition, most users (274 individuals, i.e., $88.2 \%$ ) were female. Moreover, the subjects were mostly (119 individuals, i.e., $43.6 \%$ ) in the age group of 30-39 years old. Furthermore, most of them $(65.5 \%)$ had a BS degree. Regarding computer literacy, some $66 \%$ of users did not have enough computer literacy to use information systems. However, 178 users $(62.7 \%)$ declared that their computer literacy was at the average level. Among them, only 90 users (34.1\%) had the ICDL (International Computer Driving License) certificate.
Table 5 Comparison between HIS and SAP-HR

\begin{tabular}{|c|c|c|c|c|c|c|}
\hline \multirow[t]{2}{*}{ IsoMetrics scale } & \multicolumn{2}{|l|}{ Mean } & \multirow[t]{2}{*}{$T$} & \multirow[t]{2}{*}{ df } & \multirow[t]{2}{*}{$p$} & \multirow[t]{2}{*}{$d$} \\
\hline & SAP-HR & HIS & & & & \\
\hline Suitability for the task & 2.30 & 3.04 & 20.35 & 284 & $<0.001$ & 0.74 \\
\hline Self-descriptiveness & 2.82 & 2.86 & 1.04 & 284 & 0.298 & 0.004 \\
\hline Controllability & 3.57 & 3.09 & -10.51 & 284 & $<0.001$ & 0.44 \\
\hline Conformity with user expectations & 3.21 & 3.14 & -1.29 & 284 & 0.195 & 0.06 \\
\hline Error tolerance & 2.82 & 2.95 & 3.57 & 284 & $<0.001$ & 0.13 \\
\hline Suitability for individualization & 2.59 & 2.57 & 0.313 & 284 & 0.755 & 0.01 \\
\hline Suitability for learning & 2.67 & 2.97 & 7.32 & 284 & $<0.001$ & 0.30 \\
\hline
\end{tabular}


Table 6 Comparison between HIS and Microsoft Word (Version 2.0)

\begin{tabular}{|c|c|c|c|c|c|c|}
\hline \multirow[t]{2}{*}{ IsoMetrics scale } & \multicolumn{2}{|l|}{ Mean } & \multirow[t]{2}{*}{$T$} & \multirow[t]{2}{*}{ df } & \multirow[t]{2}{*}{$p$} & \multirow[t]{2}{*}{$d$} \\
\hline & Microsoft Word & HIS & & & & \\
\hline Suitability for the task & 3.84 & 3.04 & -21.59 & 284 & $<0.001$ & 0.79 \\
\hline Self-descriptiveness & 3.98 & 2.86 & -26.62 & 284 & $<0.001$ & 1.11 \\
\hline Controllability & 3.92 & 3.09 & -19.51 & 284 & $<0.001$ & 0.82 \\
\hline Conformity with user expectations & 3.75 & 3.14 & -12.65 & 284 & $<0.001$ & 0.60 \\
\hline Error tolerance & 3.63 & 2.95 & -17.14 & 284 & $<0.001$ & 0.67 \\
\hline Suitability for individualization & 3.64 & 2.57 & -18.39 & 284 & $<0.001$ & 1.06 \\
\hline Suitability for learning & 3.74 & 2.97 & -18.77 & 284 & 0.001 & 0.76 \\
\hline
\end{tabular}

\section{Results}

In this study, the viewpoints of three types of users about usability of hospital information systems were considered. Figure 1 shows the users' viewpoints regarding the usability of HIS in Iran.

The mean value of HIS was compared with that of IS-H*med, SAP-HR, and Microsoft word separately, using $p$-values and $t$-tests. Figure 1 shows that the value of scale "conformity with user expectations" is higher than the others; yet, compared with IS-H*med, it has a lower value. The comparison between HIS and IS-H*med reveals that HIS is significantly more usable than IS-H*med with respect to all principles except conformity with user expectations. Regarding this principle, the following are among the points to be considered consistently by HIS designers: predictability of the time needed to perform a task, anticipation of the screen in the following processing sequence, defining the same function keys throughout the program for the same functions, emergence of messages in the same location.

As mentioned earlier, IS-H*med, SAP-HR, and Microsoft Word for Windows, Version 2 were evaluated by Hamborg et al. [21], Gruber [31], and Gediga et al. [15], respectively. In Tables 4, 5, and 6, the IsoMetrics mean value of HIS (evaluated by the present researchers) is compared with that of the other three evaluations in terms of $t$, df (Degree of Freedom), $p$ value and $\mathrm{d}$.

According to Table 5, HIS is significantly more usable on scales of suitability for the task, error tolerance, and suitability for learning.

As it can be seen in Table 6, usability of HIS is rated low from the users' point of view. In fact, HIS does not meet the ergonomic quality of a standard windows application.

Figure 2 shows the IsoMetrics scale means of HIS, IS-H*med, SAP-HR and Microsoft Word (Version 2.0). Figure 2 and Tables 4 and 5 show that the usability of HIS is rated higher than that of IS-H*med and SAP-HR, from the users' point of view. However, the word processing software is more usable than all these. In other words, from the users' point of view, Microsoft Word meets the ergonomic quality more.

\section{Conclusions}

IsoMetrics is a reliable and suitable technique for HIS evaluation $[15,21]$. It is a technique to evaluate the usability of software applications with respect to the international standard ISO 9241 part 10. In this research compared results of evaluation of four softwares using IsoMetrics. The comparison between HIS and IS-H*med showed that the former was significantly rated higher than the latter on all IsoMetrics scales except "conformity with user expectations". Therefore, it is suggested that hospital information system designers pay more attention to the following points:

- Predictability of the time needed to perform a task

- Anticipation of the screen in the following processing sequence

- Defining the same function keys throughout the program for the same functions

- Emergence of messages in the same location

The scale mean of suitability for the task in HIS is 3.04. It seems that HIS designers do pay attention to the suitability of HIS for the task, but apparently this much attention is not enough. Many research results have shown that inattention to the scale "suitability for the task" increases the amount of error, which will in turn have a negative impact on tasks [22, 24, 32].

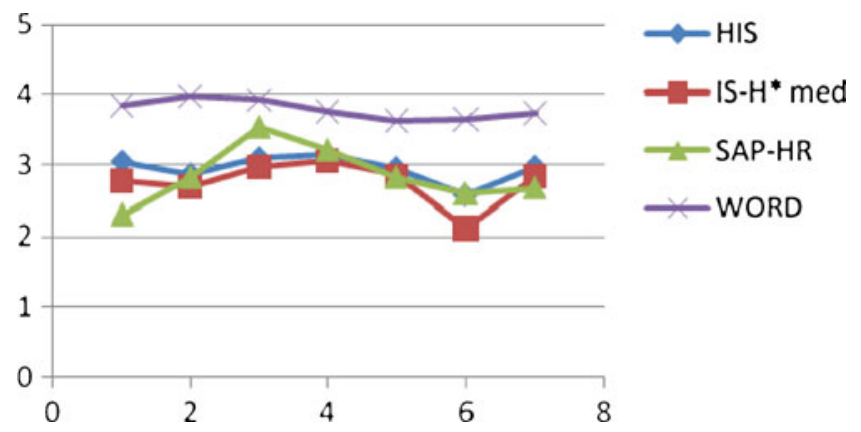

Fig. 2 IsoMetrics scale means of HIS, and IS-H*med, SAP-HR and Microsoft Word (Version 2.0) 
Regarding the principle "suitability for the task", one of the questions asked whether the software helped the users to perform their task. In response to the above question, $23.9 \%$ of the subjects of the present study believed that the HIS did not help them with performing their task; rather, they believed that it acted as an obstacle. Moreover, in a study as "A usability evaluation of four commercial dental computer-based patient record systems" conducted by Thyvalikakath et al. (2008), it was shown that $28 \%$ of users failed to perform their duties when using the system [27]. In their study, $30 \%$ of users even did their duties wrongly due to the information system. They pointed out that it was necessary to do more studies about documentation errors while using the hospital information system. Many studies also revealed that a decrease in the HIS usability led to an increase in the errors committed in performing the task $[22,24,33,34]$. Such errors have a negative effect on the task output.

The mean of "suitability for learning" in HIS was rather low (2.98). However, in a study done by Thyvalikakath et al. on dental computer-based patient record system, suitability for learning was found to be satisfactory [27]. Therefore, it is suggested that the country's HIS designers pay more attention to "suitability for learning".

The results show that hospital information system in Iran is average in terms ergonomic quality. It is to be mentioned that the ergonomic quality of an information system should be determined with regard to its context [35]. That is why, in the present study, this quality was evaluated with regard to the user types (nurses, users of paraclinic units, and department secretaries).

This study was done based on IsoMetrics short which has certain weaknesses; i.e., the cause of users' dissatisfaction and of the problems existing in the information system cannot be determined. To discover the cause of such problems and weak points, IsoMetrics long [21] is needed. In addition to this type of IsoMetrics, such techniques as user tests [36] and walkthroughs [33] can also be used.

Walkthrough is the superficial examination of a computer program before running it by reading the source code (program instructions). Walkthrough aims at identifying the possible errors in the initial stages of information system development. When we had received the evaluator reports we began the user tests, hoping to detect more possible problems in the use of terminology databases and at the same time compare the results the expert evaluation with the observations of the users [37].

One of the important things is that the evaluators must pay attention to the number of users. Cohan (1988) found out that the number of users was a factor affecting the results [38]. In this research study, the viewpoints of 285 users were considered while Gruber [31] and Gediga [15] studied the viewpoints of only 28 and 55 users in their studies, respectively.

It should be noted that the evaluation of information systems is a complex process because all human, technical and organizational aspects should be considered [39].

Acknowledgments The authors would like to extend their gratitude to professor Hamborg for providing them with questionnaires and articles related to IsoMetrics.

Conflict of interest For doing this research have not use any financial support from any organization. The authors declare that they have no conflict of interest.

Open Access This article is distributed under the terms of the Creative Commons Attribution Noncommercial License which permits any noncommercial use, distribution, and reproduction in any medium, provided the original author(s) and source are credited.

\section{References}

1. Shahmoradi, L., Ahmadi, M., and Haghani, H., Determining the most important evaluation indicators of healthcare information systems (HCIS) in Iran. Health Inform. Manag. J. 36(1):13.

2. Leclercq, A., The perceptual evaluation of information systems using the construct of user satisfaction: case study of a large French group. ACM SIGMIS Database 38(2):60, 2007.

3. Gray, P., Manager's guide to making decisions about information systems. 2006.

4. Davis, N., and LaCour, M., Introduction to health information technology, 1st edition. W.B. Saunders Company, Philadelphia, 2002.

5. Marreel, R., and McLellan, J., Information management in health care. Delmar Publishers, USA, 1999.

6. McWay, D. C., Today's health information management: an integrated approach. Delmar Cengage Learning, 2007.

7. Green, M., and Bowie, M., Essential of health information management: principles and practices. Thomson Delmar Learning, USA, 2005.

8. Latour, K., and Eichenwald, S., Health information management: concepts, principles, and practice. American Health Information Management Association, 2002.

9. Nirel, N., et al., The impact of an integrated hospital-community medical information system on quality and service utilization in hospital departments. Int. J. Med. Informat. 2010.

10. Oroviogoicoecheaa, C., and Watson, R., A quantitative analysis of the impact of a computerised information system on nurses' clinical practice using a realistic evaluation framework. Int. J. Med. Informat. 78(12):839-849, 2009.

11. Englebardt, S., and Nelson, R., Health care informatics: an interdisciplinary approach. Mosby, Denvers, 2002.

12. Wager, K., Managing health care information systems: a practical approach for health care executives. Wiley, USA, 2005.

13. Abdelhak, M., Grostick, S., and Hanken, M. A., Health information: management of strategic resource. W.B. Saunders Company, USA, 2007.

14. Brender, J., Handbook of evaluation methods for health informatics. Elsevier, USA, 2006.

15. Gediga, G., Hamborg, K., and Düntsch, I., IsoMetrics: an usability inventory supporting summative and formative evaluation of software systems. Behav. Inform. Tech. 18(3):1018-1022, 1999. 
16. Shortliffe, E., et al., Medical informatics: computer applications in health care and biomedicine (health informatics). Springer, 2003.

17. Doreen, N., et al., Toward an evaluation framework for electronic health records initiatives: a proposal for an evaluation framework. 2004.

18. Littlejohns, P., Wyatt, J., and Garvican, L., Evaluating computerised health information systems: hard lessons still to be learnt. Br. Med. J. 326(7394):860, 2003.

19. Informatics, T.U.K.I.o.H., Project Review and Objective Evaluation (PROBE) for electronic patient and health record projects. The United Kingdom Institute of Health Informatics, 2001.

20. Delone, W., and McLean, E., The DeLone and McLean model of information systems success: a ten-year update. J. Manag. Inf. Syst. 19(4):9-30, 2003.

21. Hamborg, K., Vehse, B., and Bludau, H., Questionnaire based usability evaluation of hospital information systems. Electron. $J$. Inform. Syst. Eval. 7(1):21-30, 2004.

22. Bates, W., Reducing the frequency of errors in medicine using information technology. J. Am. Med. Informat. Assoc. 8(4): 299, 2001.

23. Johnson, C., Johnson, T., and Zhang, J., Increasing productivity and reducing errors through usability analysis: a case study and recommendations. In: Proc AMIA Symp., 2000.

24. Kushniruk, A., et al., Technology induced error and usability: the relationship between usability problems and prescription errors when using a handheld application. Int. J. Med. Informat. 74 (7-8):519-526, 2005.

25. Rodriguez, N., et al., A usability study of physicians interaction with a paper-based patient record system and a graphical-based electronic patient record system. In: Proc AMIA Symp., 2002.

26. Rose, A., et al., Using qualitative studies to improve the usability of an EMR. J. Biomed. Inform. 38(1):51-60, 2005.
27. Thyvalikakath, T. P., et al., A usability evaluation of four commercial dental computer-based patient record systems. $J$. Am. Dent. Assoc. 139(12):1632-1642, 2008.

28. Thyvalikakath, T., Schleyer, T., and Monaco, V., Heuristic evaluation of clinical functions in four practice management systems: a pilot study. JADA 138(2):209-218, 2007.

29. Schleyer, T., Spallek, H., and Hernandez, P., A qualitative investigation of the content of dental paper-based and computerbased patient record formats. J. Am. Med. Informat. Assoc. 14 (4):515-526, 2007.

30. Schleyer, T., et al., Clinical computing in general dentistry. J. Am. Med. Informat. Assoc. 13(3):344-352, 2006.

31. Gruber, C., Arbeitseffizienz im Büro. Psychische Einflüsse auf SAP R/ 3unterstützte Arbeitsprozesse[online]. University of Würzburg, 2000.

32. Horsky, J., Kaufman, D., and Patel, V., The cognitive complexity of a provider order entry interface. American Medical Informatics Association, 2003.

33. Bias, R., Interface-Walkthroughs: efficient collaborative testing. IEEE Softw. 8(5):94-95, 1991.

34. Zhang, J., et al., A cognitive taxonomy of medical errors. $J$. Biomed. Inform. 37(3):193-204, 2004.

35. ISO 9241-11 Ergonomic requirements for office work with visual display terminals (VDTs): Guidance on usability specifications andd measures, 1998.

36. Dumas, J., and Redish, J., A practical guide to usability testing. Intellect Ltd., 1999.

37. Marcos, M.-C., et al., Usability evaluation of online terminology databases. Hipertext.net, Yearbook. Vol. 4. 2004: The Information Science Section of the Communication Department of the Pompeu Fabra University.

38. Cohen, J., Statistical power analysis for the behavioral sciences. Lawrence Erlbaum, 1988.

39. Yusof, M., et al., Investigating evaluation frameworks for health information systems. Int. J. Med. Informat. 77(6):377-385, 2008. 